\title{
17
}

\section{Growing Up in Times of COVID-19: When a Window of Opportunity is Temporarily Closed}

\author{
Loes Keijsers and Anne Bülow
}

In the spring of 2020, COVID-19 spread across the globe and many governments took restrictive measures to prevent a further spread. Even though adolescents, here defined as youths aged $12-25$ years, are not a high-risk group from an epidemiological viewpoint, school closures and social distancing measures had a tremendous impact on their daily lives. Adolescence is characterized by opportunities for personal growth, for establishing friendships that last a lifetime, for falling in love for the very first time, and for learning how to cope with stress. Simultaneously, adolescents are vulnerable for psychological problems, with approximately one out of five facing emotional problems, such as anxiety problems or depression (Kessler et al. 2005). In terms of social health, loneliness affects adolescents more than any other age group (Qualter et al. 2015). This chapter reflects on the psychological and social consequences of COVID-19 on adolescents while we are in the midst of the first wave. The aim is to provide concrete advice on how society, parents, and professionals can create optimal circumstances for promoting the growth of the next generations in a new common.

L. Keijsers $(\bowtie) \bullet$ A. Bülow

Department of Developmental Psychology, Tilburg School of Social and Behavioral Sciences, Tilburg, The Netherlands

Department of Psychology, Education \& Child Studies, Erasmus School of Social and Behavioural Sciences, Rotterdam, The Netherlands e-mail: keijsers@essb.eur.nl; bulow@essb.eur.nl

E. Aarts et al. (eds.), The New Common, https://doi.org/10.1007/978-3-030-65355-2_17 


\section{Attainment of Developmental Tasks}

When the body is ripe, and society requires, and the self is ready to achieve a certain task, the teachable moment has come. (Havighurst 1948)

Adolescents mature by the accomplishment of developmental tasks, by societies' predefined stepping stones (Havighurst 1948). These tasks include forming friendships and romantic relationships, achieving independence from parents, rituals of entry into adulthood (e.g., graduation), and selecting and preparing for an occupation. Society as a whole and also parents and adolescents themselves have a timetable of expectations regarding when a child should be able to accomplish these tasks (Dekovic et al. 1997). For instance, 15 year olds should be able to maintain friendships and solve a conflict on their own. Being "on schedule" provides youths with a sense of pride and meaning in life and is related to emotional well-being. Delay on the other hand, comes with a price of increased psychological problems and lower selfesteem (Seiffge-Krenke and Gelhaar 2008). Hence, even in times of a crisis, society, educators, and parents need to allow for these critical maturation tasks to be attained at the right moment.

\section{Social Deprivation}

As any other human being, adolescents have a fundamental need to belong, that is, to form and maintain high-quality, intimate, and stable relationships with others (Baumeister and Leary 1995). Whereas adults typically rely on their romantic partners for comfort, intimacy, and understanding, close friends play this pivotal role in the lives of teens (De Goede et al. 2009). In the context of close friendships, adolescents develop a set of social skills needed to function later in life, such as keeping promises, solving conflicts, and disclosing secrets (Frijns et al. 2013). Through the exploration of sexuality and romance with age-mates adolescents, they gradually learn how to engage in intimate relationships that are pleasant and long-lasting (van de Bongardt 2019). Moreover, in the ongoing search for the self, conversations with friends help an adolescent to form a stable identity (Reis and Youniss 2004). Friendships, in sum, are not only a source of great joy in adolescents' lives, they are fundamental for learning how to cope with stress, how to maintain relationships, and form the basis for future growth and maturation. 
During the COVID-19 outbreak in 2020, we assessed how the lockdown had affected friendships as part of the ADAPT project (Keijsers et al. 2017). Among 178 Dutch middle adolescents (age $=14.25$ ( $\mathrm{SD}=1.63$ ), 31\% boys), we observed strong declines in time spent with friends, from 8 hours of faceto-face contact during weekdays before the lockdown to 2 hours after and, during weekend days, from 6.5 to 2 hours. Adolescents rapidly adapted to the new situation, as online contact with friends increased from 3 hours/day to 5.5 hours. Although this online communication may compensate for some of the negative effects of the sharp decrease in face-to-face contacts (Orben et al. 2020), it is still likely that adolescents missed important opportunities to obtain support and comfort from friends and romantic partners, in circumstances when these social resources were needed most. Social deprivation may also have affected their well-being. A rapid systematic review highlighted that $30-50 \%$ of the adolescents aged 12-24 were lonely during the COVID-19 lockdown (Loades et al. 2020). Feelings of loneliness may increase the risk of developing mental health problems especially when they last longer (Qualter et al. 2015; van Roekel et al. 2013). For this reason, scholars have warned of a steep increase in mental health problems in the upcoming period, including anxiety and depression (Golberstein et al. 2020; Loades et al. 2020).

\section{Independence from Parents}

Parents play a pivotal role in helping adolescents to become adults who are resilient to stress and who function adaptively in society. During adolescence, families are challenged by the increasing developmental need of adolescents to decide things for themselves. Conflicts can easily emerge on topics such as tidying the bedroom, spending time on social media, or adhering to curfews. These negative interactions are in fact helpful in pushing the parent-child relationship from a hierarchically structured relationship in which the parent has the final say to a more horizontally structured relationship with the more democratic decision-making (Branje et al. 2011). Hence, developmental growth and maturation take place when parents release control and trust their children to make wise decisions on their own (Keijsers and Poulin 2013).

In the ADAPT project (Keijsers et al. 2017), we observed the opposite change pattern. During the lockdown, instead of releasing control, parents became more protective and controlling. New rules were established by parents, mostly to reinforce governmental rules of hygiene and social distancing, such as not being allowed to see friends. Parents also introduced rules to structure the lives of their children, such as doing homework and getting up in 
time. Longitudinal analyses of eight repeated assessments indeed revealed a significant decrease in autonomy-supportive parenting during the lockdown (Bülow et al. 2020). As prohibition of contacts with friends and restriction of autonomy directly undermine the opportunities for growth, we anticipated a rise in conflicts and opposition (Van Petegem et al. 2017). However, this was only found for some families. Apparently, most parents manage to introduce and explain rules in a democratic way, and children find most of the novel rules legitimate. In fact, in some families, the increase in time spent together may have created opportunities to reinforce the relationship and improve communication (Keijsers et al. 2010). On the other hand, stress due to health or financial concerns may also trigger the use of a repressive parenting strategy, including guilt induction and love withdrawal (Van Der Kaap-Deeder et al. 2019). Such psychological control may impede on maturation processes and lead to internalizing problems, such as depressive feelings or anxiety, among adolescents. C'est la ton qui fait la musique when it comes to finding the balance between protection and promoting independence.

\section{Promoting Developmental Growth in the New Common}

Adolescents are in the midst of establishing an important foundation for developmental growth and future well-being. Adolescents need friendships, independence from parents, and rituals that mark the entry to adulthood and new phases in life, such as graduation ceremonies. The COVID-19 situation has strongly affected each of these domains. One can never truly predict how an individual's life course is affected by such a temporary situational change. In general, most adolescents will probably be resilient, and negative experiences and a short-term reduction in well-being do not doom them to an adult life full of ill-being and psychosocial problems (Cicchetti and Rogosch 2002). Likewise, adolescents who are resilient during this stressful period cannot comfortable rely on a problem-free future. The longer-term impact can only be derived from rigorous future scientific studies on adolescents. However, this should not prevent society from creating optimal circumstances for growth while we are still in the midst of the crisis.

First of all, as they are vulnerable to psychological problems, it is of pivotal importance to monitor and support adolescents. The current COVID-19 situation is one of many changes for adolescents. Social distancing undermines social support of their most intimate companions, which may lead to 
loneliness and decreased well-being. Accessible tools and informal and lowkey professional guidance are needed to prevent psychosocial problems, such as depression (Golberstein et al. 2020). Examples include eHealth tools that challenge adolescents to cope with stress, such as our recently released Grow It! application (Hillegers et al. 2020).

Second, face-to-face contact with friends is not a luxury for adolescents; it is a developmental need. Social media is a blessing for adolescents, but it cannot compensate for the richness of learning experiences and support that faceto-face interactions provide. Third, during the lockdown measures, adolescents' potential for growth and resilience was hindered because parents had to restrict opportunities for independent decision-making. In sum, in the new common, parents, teachers, and professionals should protect adolescents only when needed and allow for autonomy, independent decision-making, and contact with their friends whenever possible. Even when society is locked down, the window of opportunity for growth needs to be open for adolescents. After all, if adults support youngster in acquiring social skills and personal resources during a formative period in life, the next generation will be better able to cope with stress and societal changes to come.

Acknowledgments This research was supported by a VIDI-grant from the Netherlands Organisation for Scientific Research (NWO; 452-17-011) awarded to Dr. Loes Keijsers.

\section{References}

Baumeister RF, Leary MR (1995) The need to belong: desire for interpersonal attachments as a fundamental human motivation. Psychol Bull 117(3):497-529. https:// doi.org/10.1037/0033-2909.117.3.497

Branje S, Keijsers L, van Doorn M, Meeus WHJ (2011) Interpersonal and intrapersonal processes in development of relationships in adolescence. In: Relationship pathways: from adolescence to young adulthood. SAGE Publications, Inc., London, pp 257-286

Bülow A, Keijsers L, Boele S, van Roekel E, Denissen JJA (2020) Parenting adolescents in time of a pandemic: changes in relationship quality, autonomy support and parental control. In Preparation. doi: https://doi.org/10.17605/ OSF.IO/SVYAU

Cicchetti D, Rogosch FA (2002) A developmental psychopathology perspective on adolescence. J Consult Clin Psychol 70(1):6-20. https://doi.org/10.1037/0022006X.70.1.6 
De Goede IHA, Branje SJT, Meeus WHJ (2009) Developmental changes and gender differences in adolescents' perceptions of friendships. J Adolesc 32(5):1105-1123. https://doi.org/10.1016/j.adolescence.2009.03.002

Dekovic M, Noom MJ, Meeus W (1997) Expectations regarding development during adolescence: parental and adolescent perceptions. J Youth Adolesc 26(3):253-272. https://doi.org/10.1007/s10964-005-0001-7

Frijns T, Finkenauer C, Keijsers L (2013) Shared secrets versus secrets kept private are linked to better adolescent adjustment. J Adolesc 36(1):55-64. https://doi. org/10.1016/j.adolescence.2012.09.005

Golberstein E, Wen H, Miller BF (2020) Coronavirus disease 2019 (COVID-19) and mental health for children and adolescents. JAMA Pediatr 174(9):819-820. https://doi.org/10.1001/jamapediatrics.2020.1456

Havighurst R (1948) Developmental tasks and education. https://psycnet.apa.org/ record/1950-00529-000

Hillegers MHJ, Keijsers L, Legerstee J (2020) Grow It! app

Keijsers L, Poulin F (2013) Developmental changes in parent-child communication throughout adolescence. Dev Psychol 49(12):2301-2308. https://doi. org/10.1037/a0032217

Keijsers L, Branje SJT, Vander Valk IE, Meeus W (2010) Reciprocal effects between parental solicitation, parental control, adolescent disclosure, and adolescent delinquency. J Res Adolesc 20(1):88-113. https://doi. org/10.1111/j.1532-7795.2009.00631.x

Keijsers L, Boele S, Bülow A (2017) ADAPT project (Assessing the Dynamics between Adaptation and Parenting in Teens). https://doi.org/osf.io/svyau

Kessler RC, Berglund P, Demler O, Jin R, Merikangas KR, Walters EE (2005) Lifetime prevalence and age-of-onset distributions of DSM-IV disorders in the National Comorbidity Survey Replication. Arch Gen Psychiatry 62(6):593-602. https://doi.org/10.1001/archpsyc.62.6.593

Loades ME, Chatburn E, Higson-Sweeney N, Reynolds S, Shafran R, Brigden A et al (2020) Rapid systematic review: the impact of social isolation and loneliness on the mental health of children and adolescents in the context of COVID-19. J Am Acad Child Adolesc Psychiatry 59(11):1218.e3-1239.e3. https://doi. org/10.1016/j.jaac.2020.05.009

Orben A, Tomova L, Blakemore S (2020) The effects of social deprivation on adolescent social development and mental health. https://psyarxiv.com/7afmd/ download?format=pdf

Qualter P, Vanhalst J, Harris R, Van Roekel E, Lodder G, Bangee M, Verhagen M (2015) Loneliness across the life span. Perspect Psychol Sci 10(2):250-264. https://doi.org/10.1177/1745691615568999

Reis O, Youniss J (2004) Patterns in identity change and development in relationships with mothers and friends. J Adolesc Res 19(1):31-44. https://doi. org/10.1177/0743558403258115 
Seiffge-Krenke I, Gelhaar T (2008) Does successful attainment of developmental tasks lead to happiness and success in later developmental tasks? A test of Havighurst's (1948) theses. J Adolesc 31(1):33-52. https://doi.org/10.1016/j. adolescence.2007.04.002

van de Bongardt D (2019) Youth's sexual relationships and development. In: Psychosocial development in adolescence, pp 160-176. https://doi.org/10.432 4/9781315165844-10

Van Der Kaap-Deeder J, Soenens B, Mabbe E, Dieleman L, Mouratidis A, Campbell R, Vansteenkiste M (2019) From daily need experiences to autonomy-supportive and psychologically controlling parenting via psychological availability and stress. Parenting 19(3):177-202. https://doi.org/10.1080/15295192.2019.1615791

Van Petegem S, Vansteenkiste M, Soenens B, Audenaert E (2017) When do adolescents accept or defy to maternal prohibitions? The role of social domain and communication style. J Youth Adolesc 46:1022-1037. https://doi.org/10.1007/ s10964-016-0562-7

van Roekel E, Goossens L, Verhagen M, Wouters S, Engels RCME, Scholte RHJ (2013) Loneliness, affect, and adolescents' appraisals of company: an experience sampling method (ESM) study. J Res Adolesc 24(2):350-363. https://doi. org/10.1111/jora.12061

Open Access This chapter is licensed under the terms of the Creative Commons Attribution 4.0 International License (http://creativecommons.org/licenses/by/4.0/), which permits use, sharing, adaptation, distribution and reproduction in any medium or format, as long as you give appropriate credit to the original author(s) and the source, provide a link to the Creative Commons licence and indicate if changes were made.

The images or other third party material in this chapter are included in the chapter's Creative Commons licence, unless indicated otherwise in a credit line to the material. If material is not included in the chapter's Creative Commons licence and your intended use is not permitted by statutory regulation or exceeds the permitted use, you will need to obtain permission directly from the copyright holder.

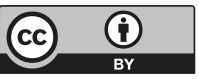

